\title{
FIVE-FACTOR MODEL PERSONALITY PROFILES: THE DIFFERENCES BETWEEN ALCOHOL AND OPIATE ADDICTION AMONG FEMALES
}

\author{
Diana Raketic ${ }^{1}$, Jasmina V. Barisic ${ }^{2}$, Snezana M. Svetozarevic ${ }^{3}$, Tatjana Gazibara ${ }^{4}$, \\ Darija Kisic Tepavcevic $^{4,5}$ \& Srdjan D. Milovanovic ${ }^{2,5}$ \\ ${ }^{1}$ Specialized Hospital for Addiction Diseases in Belgrade, Belgrade, Serbia \\ ${ }^{2}$ Clinic for Psychiatry, Clinical Center of Serbia, Belgrade, Serbia \\ ${ }^{3}$ Faculty of Philosophy, University of Belgrade, Belgrade, Serbia \\ ${ }^{4}$ Institute of Epidemiology, Faculty of Medicine, University of Belgrade, Belgrade, Serbia \\ ${ }^{5}$ School of Medicine, University of Belgrade, Belgrade Serbia
}

received: 10.9.2016;

revised: 3.11.2016;

accepted: 7.12 .2016

\section{SUMMARY}

Background: The prevalence of female alcohol and substance abusers has markedly increased. The main objective of this research was to explore personality profiles among females who had alcohol and opiate dependence.

Aim: The aim of the study is to analyse if there is differences in personality profiles of females addicted to alcohol and opiates. We hypothesized that there might be significant differences in personality profiles among subgroups of women who present with alcohol and opiate use disorders.

Subjects and methods: Of 157 consecutive women with diagnosis of alcohol/opiate addiction, 62 fulfilled following inclusion criteria: age 19-45 years, abstinence from alcohol and opiates for at least 10 days prior to enrollment. Alcohol-dependent group consisted of 30 females, while opiate-dependent group consisted of 32 females. The control group involved 30 age-matched randomly chosen healthy women. The data were collected using the Revised NEO Personality Inventory (NEO-PI-R). The multiple stepwise discriminant analysis was used to determine relations between personality traits and the probability of belonging to one of the study groups.

Results: Significant differences in the NEO-PI-R scores were observed between groups for all main personality traits except for Openness to Experience. Compared with controls, substance-dependent women scored significantly higher on Neuroticism and lower on Conscientiousness. Opiate-dependent females scored the highest on Neuroticism and on Extraversion and lowest on Agreeableness and on Conscientiousness. Alcohol-dependent females scored higher on Conscientiousness and lower on Neuroticism compared to opiate-dependent women.

Conclusions: The results of our study confirmed significant characteristics in personality profiles among females with alcohol and opiate dependence, as well as the difference between these two groups of substance abusers and their healthy controls. The distinct personality characteristics among different groups of substance addicted women should be taken into account when creating the most effective program of prevention and therapeutic approaches in this specific cohort.

Key words: addiction - females - five-factor model

\section{INTRODUCTION}

Over the past decades the prevalence of alcohol and substance abuse has markedly increased worldwide (Brady \& Li 2014, Hasin et al. 2015). Research in this area has been mainly focused on male substance abusers. A growing body of evidence emphasizes the importance of female-specific studies in all areas of substance abuse research (Schmitt et al. 2008, Tuchman 2010, Boykoff et al. 2010, Abulseoud et al. 2013). Specifically, epidemiological and clinical evidence suggests that the number of female alcohol and substance abusers is increasing, while the predictors for alcohol and substance use disorders as well as the addiction progression are gender sensitive (Tuchman 2010, Dubey et al. 2010). Therefore, further exploration of female personality profiles in different type of substance use and addictive disorders may provide important leads towards better prediction, prevention, and treatment of these disorders among females.
A number of studies suggested that wide range of personality characteristics are related to substance addiction (Hopwood et al. 2007, Tuchman 2010, Boykoff et al. 2010). Although a strong association of personality traits with tendency towards alcohol and drug abuse is well recognized, the nature of this relationship remains unclear (Flory et al. 2002). Some studies indicated that personality pathology results from substance abuse (Barnes 1983, Sher \& Trull 1994), reflecting not only the toxic effect of substances, but also severe psychosocial stress associated with heavy drug and alcohol use. Other studies have offered the opposite view, i.e., that personality profiles, either directly or indirectly, could be a predisposing factor for substance abuse in general (Sher \& Trull 1994, Flory et al. 2002, Milivojevic et al. 2012, Mirnics et al. 2013). For example, certain personality characteristics may share a common biological pathway with substance abuse, thereby affecting substance-related behaviors (Robinet et al. 1998, Milivojevic et al. 2012). 
Bearing in mind all above mentioned, we hypothesized that there might be significant differences in personality profiles among females with alcohol and opiate use disorders, as well as between these two groups of substance users and their healthy age-matched counterparts, what was the main objective of our research.

\section{MATERIAL AND METHODS}

\section{Participants}

Consecutive female outpatients referred to the Specialized Hospital for Addiction Diseases in Belgrade (Serbia) between January 1, 2015 and July 1, 2015 were invited to participate in this cross-sectional study. The main inclusion criterion was being diagnosed with alcohol or opiate (heroine) use disorder based on the International Classification of Diseases $10^{\text {th }}$ revision (ICD-10) criteria. Other inclusion criteria were age (19 to 45 years), diagnosis of substance use persisting for at least 5 years, abstinence from alcohol and opiates for at least 10 days prior to enrollment and personality testing (completed detoxification and some psycho-physical stabilization were considered important for the validity and reliability of personality scores). The general exclusion criteria were presence of substance use disorders other than alcohol and opiates (heroine), pre-existing major medical illness and/or psychiatric disorders, and intelligence quotient (IQ) below 90 points.
Of 157 women with diagnosis of alcohol or opiate addiction seen for treatment in this period, 62 fulfilled the criteria for participation in the study. The first group consisted of 30 females who had alcohol use disorder, while the second group consisted of 32 females who had heroin use disorder. There were no subjects with comorbid alcohol and opioid use. The control group consisted of 30 age-matched women not diagnosed with any mental-health disorders who were randomly chosen from the primary health centre in Belgrade (Serbia) during the study period. All participants provided written informed consents. The study was approved by the Ethical Committee of the School of Medicine, University of Belgrade.

\section{Instruments}

The participants completed the Revised NEO Personality Inventory (NEO-PI-R), validated previously for use in Serbian speaking population (Knežević et al. 2004). The NEO-PI-R questionnaire measures five major domains of personality, notably Neuroticism $(\mathrm{N})$, Extraversion (E), Openness to Experience (O), Agreeableness (A) and Conscientiousness (C), each consisting of six facets or lower order traits. The NEOPI-R contains 240 items answered on a five-point Likert scale ranging from "strongly agree" to "strongly disagree".

Table 1. Socio-demographic characteristics of study groups

\begin{tabular}{|c|c|c|c|c|}
\hline Variable & $\begin{array}{l}\text { Opiate dependent } \\
\text { sample }(n=32)\end{array}$ & $\begin{array}{l}\text { Study group s } \\
\text { Alcohol dependent } \\
\text { sample }(n=30)\end{array}$ & $\begin{array}{c}\text { Comparison } \\
\text { sample }(n=30)\end{array}$ & $P$ value \\
\hline \multicolumn{5}{|l|}{ Current age (years) } \\
\hline Mean $\pm \mathrm{SD}$ & $35.4 \pm 5.2$ & $39.9 \pm 5.1$ & $36.1 \pm 5.6$ & \multirow[t]{2}{*}{0.175} \\
\hline Range & $19-42$ & $29-45$ & $22-44$ & \\
\hline \multicolumn{5}{|l|}{ Education (years), No (\%) } \\
\hline Primary (1-8) & $5(15.6)$ & $3(10.0)$ & $0(0.0)$ & \multirow{3}{*}{0.116} \\
\hline Secondary (9-12) & $25(78.1)$ & $20(66.7)$ & $27(90.0)$ & \\
\hline University $(13+)$ & $2(6.3)$ & $7(23.3)$ & $3(10.0)$ & \\
\hline \multicolumn{5}{|c|}{ Current employment status, No (\%) } \\
\hline Employed & $11(34.4)$ & $23(76.7)$ & $24(80.0)$ & \multirow[t]{2}{*}{0.002} \\
\hline Unemployed $^{\mathrm{a}}$ & $21(65.6)$ & $7(23.3)$ & $6(20.0)$ & \\
\hline \multicolumn{5}{|l|}{ Marital status, No (\%) } \\
\hline Single (never married $)^{\mathrm{a}}$ & $17(53.1)$ & $6(20.0)$ & $7(23.3)$ & \multirow{4}{*}{0.037} \\
\hline Married/cohabiting & $9(28.1)$ & $15(50.0)$ & $17(56.7)$ & \\
\hline Widowed & $1(3.1)$ & $2(6.7)$ & $2(6.7)$ & \\
\hline Separated/divorced & $5(15.7)$ & $7(23.3)$ & $4(13.3)$ & \\
\hline \multicolumn{5}{|l|}{ Number of children, No (\%) } \\
\hline Without child ${ }^{\mathrm{a}}$ & $25(78.1)$ & $8(26.7)$ & $10(33.3)$ & \multirow{4}{*}{$<0.001$} \\
\hline One child & $6(18.8)$ & $8(26.7)$ & $5(16.7)$ & \\
\hline Two children & $1(3.1)$ & $13(43.3)$ & $14(46.7)$ & \\
\hline Three children & $0(0.0)$ & $1(3.3)$ & $1(3.3)$ & \\
\hline
\end{tabular}


Table 2. Descriptive characteristics of NEO-PI-R domains of study groups

\begin{tabular}{|c|c|c|c|c|c|}
\hline NEO-PI-R domains & $\begin{array}{l}\text { Opiate dependent } \\
\text { sample }(n=32)\end{array}$ & $\begin{array}{l}\text { Study groups } \\
\text { Alcohol dependent } \\
\text { sample }(\mathrm{n}=30)\end{array}$ & $\begin{array}{c}\text { Comparison } \\
\text { sample }(n=30)\end{array}$ & $\mathrm{F}^{\mathrm{a}}$ & $\mathrm{P}$ value \\
\hline $\begin{array}{l}\text { Neuroticism } \\
\text { Mean } \pm \text { SD }\end{array}$ & $153.0 \pm 20.9 * *$ & $148.0 \pm 21.6^{* *}$ & $132.1 \pm 19.1$ & 8.747 & $<0.001$ \\
\hline $\begin{array}{l}\text { Extraversion } \\
\text { Mean } \pm \text { SD }\end{array}$ & $160.0 \pm 10.4^{*}$ & $151.2 \pm 13.7$ & $153.2 \pm 12.9$ & 4.412 & 0.015 \\
\hline $\begin{array}{l}\text { Openness to Experience } \\
\text { Mean } \pm \text { SD }\end{array}$ & $162.6 \pm 15.7$ & $161.1 \pm 18.0$ & $160.0 \pm 19.1$ & 0.168 & 0.845 \\
\hline $\begin{array}{l}\text { Agreeableness } \\
\text { Mean } \pm \text { SD }\end{array}$ & $149.0 \pm 16.2 * *$ & $154.0 \pm 11.1$ & $159.4 \pm 11.9$ & 4.675 & 0.012 \\
\hline $\begin{array}{l}\text { Conscientiousness } \\
\text { Mean } \pm \text { SD }\end{array}$ & $150.7 \pm 21.7 * *$ & $165.0 \pm 16.4^{*}$ & $170.6 \pm 18.9$ & 8.852 & $<0.001$ \\
\hline
\end{tabular}

${ }^{a}$ ANOVA test; $\quad *$ Tukey's test $\mathrm{p}<0.05$ compared to controls; $\quad * *$ Tukey's test $\mathrm{p}<0.01$ compared to controls

Table 3. Descriptive characteristics of NEO-PI-R facets of study groups

\begin{tabular}{|c|c|c|c|c|c|}
\hline NEO-PI-R facets & $\begin{array}{l}\text { Opiate dependent } \\
\text { sample }(\mathrm{n}=32) \\
\text { Mean } \pm \mathrm{SD}\end{array}$ & $\begin{array}{c}\text { Study group s } \\
\text { Alcohol dependent } \\
\text { sample }(\mathrm{n}=30) \\
\text { Mean } \pm \text { SD }\end{array}$ & $\begin{array}{c}\text { Comparison sample } \\
(\mathrm{n}=30) \\
\text { Mean } \pm \text { SD }\end{array}$ & $\mathrm{F}^{\mathrm{a}}$ & $\mathrm{P}_{\text {value }} \mathrm{a}$ \\
\hline \multicolumn{6}{|l|}{ Neuroticism } \\
\hline Anxiety & $26.2 \pm 6.1$ & $26.5 \pm 5.8$ & $24.5 \pm 5.2$ & 1.128 & 0.328 \\
\hline Angry Hostility & $25.1 \pm 4.7 *$ & $24.0 \pm 2.9^{*}$ & $22.5 \pm 4.0$ & 3.678 & 0.029 \\
\hline Depression & $27.9 \pm 6.0 * *$ & $25.9 \pm 5.5^{*}$ & $22.2 \pm 5.1$ & 11.531 & $<0.001$ \\
\hline Self-Consciousness & $22.7 \pm 4.1^{*}$ & $24.4 \pm 4.0$ & $25.5 \pm 2.9$ & 4.373 & 0.015 \\
\hline Impulsiveness & $27.4 \pm 4.6^{* *}$ & $24.6 \pm 4.6^{*}$ & $22.4 \pm 4.9$ & 8.888 & $<0.001$ \\
\hline Vulnerability to Stress & $23.6 \pm 4.3 * *$ & $22.6 \pm 5.2 *$ & $20.0 \pm 3.9$ & 5.312 & 0.007 \\
\hline \multicolumn{6}{|l|}{ Extraversion } \\
\hline Warmth & $28.6 \pm 3.6$ & $27.6 \pm 3.9$ & $28.2 \pm 3.2$ & 0.607 & 0.547 \\
\hline Gregariousness & $26.8 \pm 5.0$ & $23.8 \pm 6.6$ & $26.7 \pm 5.4$ & 2.758 & 0.069 \\
\hline Assertiveness & $22.2 \pm 3.6$ & $22.2 \pm 4.2$ & $21.3 \pm 2.8$ & 0.583 & 0.560 \\
\hline Activity & $26.2 \pm 3.0$ & $25.1 \pm 2.7$ & $25.7 \pm 3.4$ & 0.907 & 0.407 \\
\hline Excitement Seeking & $30.1 \pm 9.6^{* *}$ & $25.6 \pm 4.1$ & $24.8 \pm 5.3$ & 12.705 & $<0.001$ \\
\hline Positive Emotions & $26.1 \pm 3.2$ & $26.8 \pm 2.4$ & $26.4 \pm 2.4$ & 0.492 & 0.613 \\
\hline \multicolumn{6}{|l|}{ Openness to Experience } \\
\hline Fantasy & $26.1 \pm 6.5$ & $23.4 \pm 6.4$ & $24.7 \pm 5.7$ & 0.965 & 0.385 \\
\hline Aesthetics & $27.8 \pm 5.0$ & $29.2 \pm 3.8$ & $27.7 \pm 3.8$ & 1.358 & 0.263 \\
\hline Feelings & $31.1 \pm 4.7$ & $29.9 \pm 4.3$ & $29.7 \pm 4.9$ & 0.752 & 0.474 \\
\hline Actions & $23.2 \pm 4.1$ & $24.1 \pm 3.4$ & $22.7 \pm 3.2$ & 1.247 & 0.292 \\
\hline Ideas & $27.8 \pm 6.5$ & $26.5 \pm 4.1$ & $26.8 \pm 6.4$ & 0.388 & 0.680 \\
\hline Values & $26.5 \pm 3.5$ & $27.4 \pm 3.8$ & $28.4 \pm 3.5$ & 2.028 & 0.138 \\
\hline \multicolumn{6}{|l|}{ Agreeableness } \\
\hline Trust & $23.6 \pm 6.1^{+}$ & $27.0 \pm 4.5$ & $25.8 \pm 3.9$ & 3.780 & 0.027 \\
\hline Straightforwardness & $23.5 \pm 3.1$ & $25.1 \pm 2.7$ & $24.0 \pm 2.8$ & 2.534 & 0.085 \\
\hline Altruism & $28.5 \pm 3.6$ & $29.2 \pm 3.5$ & $29.3 \pm 3.7$ & 0.460 & 0.633 \\
\hline Compliance & $21.1 \pm 5.5^{+}$ & $24.5 \pm 4.2$ & $22.8 \pm 5.2$ & 3.622 & 0.031 \\
\hline Modesty & $23.6 \pm 3.8$ & $24.2 \pm 4.7$ & $24.0 \pm 3.5$ & 0.206 & 0.814 \\
\hline Tender-Mindedness & $28.8 \pm 3.7$ & $29.4 \pm 3.1$ & $28.2 \pm 3.3$ & 1.002 & 0.317 \\
\hline \multicolumn{6}{|l|}{ Conscientiousness } \\
\hline Competence & $26.9 \pm 4.8$ & $28.0 \pm 4.1$ & $28.6 \pm 3.9$ & 1.431 & 0.245 \\
\hline Order & $25.5 \pm 3.9$ & $27.2 \pm 2.5$ & $27.2 \pm 3.5$ & 2.691 & 0.073 \\
\hline Dutifulness & $28.3 \pm 4.8^{*}$ & $30.5 \pm 3.1$ & $31.1 \pm 3.7$ & 6.423 & 0.002 \\
\hline Achievement Striving & $24.5 \pm 5.2$ & $26.3 \pm 4.0$ & $27.1 \pm 4.3$ & 2.672 & 0.075 \\
\hline Self-Discipline & $25.3 \pm 6.2 * *$ & $28.7 \pm 4.6$ & $29.5 \pm 5.2$ & 5.316 & 0.007 \\
\hline Deliberation & $20.3 \pm 5.1 * *$ & $24.6 \pm 4.2$ & $26.4 \pm 5.8$ & 1.002 & $<0.001$ \\
\hline
\end{tabular}

\footnotetext{
${ }^{a}$ ANOVA test; *Tukey's test $\mathrm{p}<0.05$ compared to controls; **Tukey's test $\mathrm{p}<0.01$ compared to controls;

${ }^{+}$Tukey's test $\mathrm{p}<0.05$ compared to alcohol-dependent group
} 
Diana Raketic, Jasmina V. Barisic, Snezana M. Svetozarevic, Tatjana Gazibara, Darija Kisic Tepavcevic \& Srdjan D. Milovanovic: FIVE-FACTOR MODEL PERSONALITY PROFILES: THE DIFFERENCES BETWEEN ALCOHOL AND OPIATE ADDICTION AMONG FEMALES Psychiatria Danubina, 2017; Vol. 29, No. 1, pp 74-80

Table 4. Characteristics of discriminative functions

\begin{tabular}{lccccccrr}
\hline Function & $\begin{array}{c}\text { Eigen } \\
\text { value }\end{array}$ & $\begin{array}{c}\text { \% of } \\
\text { Variance }\end{array}$ & $\begin{array}{c}\text { Cumula- } \\
\text { tive } \%\end{array}$ & $\begin{array}{c}\text { Canonical } \\
\text { Correlation }\end{array}$ & $\begin{array}{c}\text { Wilks' } \\
\text { Lambda }\end{array}$ & Chi square & df & $\mathrm{p}$ \\
\hline 1 & $0.513(\mathrm{a})$ & 84.2 & 84.2 & 0.582 & 0.603 & 43.518 & 10 & $<0.001$ \\
2 & $0.096(\mathrm{a})$ & 15.8 & 100.0 & 0.296 & 0.912 & 7.895 & 4 & 0.095 \\
\hline
\end{tabular}

\section{Statistical analysis}

Normality of the distribution was tested using the Kolomogorov-Smirnov test. Data were presented as arithmetic mean \pm standard deviation for continues variables and as absolute number and percentages for discrete variables. Differences between groups were assessed by ANOVA and post hoc Tukey's test for parametric variables and by Kruskal-Wallis and MannWhitney $U$ test for non-parametric variables. The multiple stepwise discriminant analysis was used to determine relations between independent variable (five broad personality dimensions of NEO-PI-R) and dependent variable (membership in one of the study groups). The probability value (p) of less than 0.05 was chosen as the level of statistical significance.

\section{RESULTS}

The socio-demographic characteristics of the samples are summarized in Table 1.

As shown in Table 1, there were no significant differences among study groups with respect to current age and educational level. The proportion of unemployed women was statistically higher in the opioid use disorder group compared to both alcohol use disorder group $(p=0.003)$ and control group $(p<0.01)$. Additionally, the prevalence of never-married females, as well as the percentage of women without children were significantly higher in females with opioid use disorder versus females with alcohol use disorder $(p<0.01)$ and controls $(p<0.01)$.

The descriptive characteristics of the NEO-PI-R personality characteristics in study groups are summarized in Table 2.

As seen in Table 2, statistically significant differences in NEO-PI-R scores have been observed in subjects and controls for all the main personality traits except for Openness to Experience. Compared with controls, females with substance use disorders (either alcohol or heroin) had significantly higher Neuroticism and lower Conscientiousness scores. In addition, females with heroin use disorder scored higher on Extraversion and lower on Agreeableness than both females with alcohol use disorder and controls. Females with alcohol use disorder scored higher on Conscientiousness and lower on Neuroticism than those diagnosed with heroin use disorder (Table 2).

At the facets level of the NEO-PI-R, all traits belonging to the Neuroticism domain, except Anxiety, were significantly more prominent in the opiate and alcoholdependent groups compared to controls. The Excitement Seeking facet of Extraversion made the largest contribution to the discrepancy between opiate-dependent and control groups. In the Agreeableness domain, the Trust and Compliance facet scales played statistically significant role in observed difference between opiate and alcohol-dependent females. Additionally, compared to the control group, opiate-dependent females scored significantly less on Dutifulness, Self-Discipline and Deliberation facet scales, which are included in the Conscientiousness domain (Table 3).

A multiple stepwise discriminant analysis was used to determine relations between personality traits and belonging to one of the study groups. Canonical discriminant analysis demonstrated two functions of which one was statistically significant, explaining $84.2 \%$ of the variance of belonging to one of the study groups (Table 4). The structure of this function was consisted of negative poles of Agreeableness and Conscientiousness and positive poles of Neuroticism and Extraversion domains. The Openness to Experience domain did not made a significant contribution to the discriminant function. The opiate-dependent females were on the positive pole of the latter functions (0.943), while the control group was on its negative pole (-0.656). Additionally, according to value of the centroide $(-0.361)$, the alcoholdependent females were positioned closer to the control group compared to the opiate-dependent females.

\section{DISCUSSION}

Investigation of female-specific personality profiles of different type of substance use disorders is a challenging research area. Women commonly develop substance use disorders during their reproductive period of life with numerous consequences at all levels of their psychosocial functioning (Zweben 2009). The age distribution of women with alcohol or opiate addiction in our study also confirmed this hypothesis because all substance-dependent females in our survey were in the age range from 19 to 45 years. Furthermore, the opiatedependent females in our study were younger than alcohol-dependent women, albeit not statistically significantly. However, the results from numerous studies have generally identified that opiate addiction tends to occur earlier in life (even in adolescence), while alcohol addiction develops later in life. Our study also showed that opiate-dependent group included considerably higher proportion of women who were unemployed, never-married and without children compared to the other groups, which is in accordance with preceding findings related to the significant disturbance of psychosocial functioning among opiate-dependent females (Zweben 2009, Raketic et al. 2013). 
The main objective of this research was to explore personality profiles among females with presence of alcohol and opioid dependence. Statistically significant differences in values of raw scores of the NEO-PI-R between study groups, have been observed on all main domains except on Openness to Experience, which is in line with results from other studies (Brooner et al. 1993, Hopwood et al. 2007, Dubey et al. 2010). The most prominent finding is the fact that opiate dependent women in our sample had the highest scores in Neuroticism and Extraversion domains, but at the same time had the lowest scores in the domains of Agreeableness and Conscientiousness. Numerous studies, primarily conducted in the United States and Norway, also suggested that opiate addicted females tended to have high scores on Neuroticism dimension with low scores on Conscientiousness and Agreeableness dimensions (Brooner et al. 2002, Korner \& Nordvik 2007).

In general, our results derived from the Five-factor model suggested that personality profile scores of alcohol dependent women were mainly in between opiate addicted and control groups. Hence, according to the scores of the Five-factor model, alcohol-dependent women in our sample, were close to women from the control group in terms of Extraversion, but were more neurotic and less conscientious then controls. They also presented themselves more cooperative then opiate addiced women.

Comprehensive analysis at the facets level of the NEO-PI-R in our sample of females has shown that the following facets of Neuroticism domain were statistically higher in opiate- and alcohol-dependent women as opposed to controls: Angry Hostility, Depression, Impulsiveness and Vulnerability to Stress. Numerous studies offered a picture of complex relationship between depression and disorders related to substance use, especially in the group of alcohol addicted women (Brown \& Stewart 2008, Harrell et al. 2009). Although, the finding in our study revealed that opiate-dependent women had the highest scores on Depression compared to the other two groups, the result from a number of studies highlighted that this affective disorder is not dominant characteristic among opiate-dependent females. Specifically, they commonly used to present depression by symptoms of boredom, feelings of emptiness or through negativistic or rebellious behavior (Akiskal et al. 1983). Furthermore, this finding is in line with the notion that both samples of addicted women scored significantly higher on Impulsiveness, which is in accordance with the results from other studies (Perry \& Carroll 2008, Verdejo-Garcia et al. 2008). Namely, previous studies suggested a hypothesis where this factor largely contributes to vulnerability in substance-related disorders. However, recent studies suggested that the relationship between impulsivity and addiction diseases is very intricate and multifaceted, and probably should take into account a potential cognitive and neurobiological substrate of impulsiveness (De Wit 2009). Furthermore, the Angry
Hostility trait has also been confirmed as personal characteristic of addicts through clinical manifestations of the 'typical' propensity to anger, and tendency towards the bad, irritable mood. Robinson et al. suggested that the hostility is even more pronounced in substance-dependent women compared to men (Robinson et al. 2001). Additionally, high score of substanceaddicted persons on Vulnerability to Stress has also been confirmed in numerous studies and indicated that this cohort has high sensitivity and vulnerability to stress, as well as inadequate ability to cope with stress situations (Kreek et al. 2005). On the other hand, the low score on the Consciousness domain was also identified as important characteristic of opiate-dependent persons in various studies (Walton \& Roberts 2004, Malouff et al. 2007). Analysis of the structure of Conscientiousness dimension in our study showed that subscales of Dutifulness, Deliberation and Self-Discipline made the largest contribution to discrepancy of scores between opiate dependent females and the other two groups. This finding is in agreement with common clinical impression that opiate-addicted persons, in the psychotherapeutic process, tended to have passive reactions, and are generally less focused on the target, easily distracted and prone to giving up.

The comprehensive analyses at the facets level of the NEO-PI-R in our study have shown that subscale of Excitement Seeking made the largest contribution in the discrepancy between opiate-dependent and control groups in domain of Extraversion, which is in line with the findings from similar studies (Acton 2003, Svrakic \& Cloninger 2010). It has been suggested that novelty seeking, in general, as personality trait associated with exploratory activity in response to novel stimulation, impulsive decision making and extravagance could be assumed as the basis for substance-abuse vulnerability (Acton 2003, Svrakic \& Cloninger 2010).

The most prominent deviation of the results obtained in our study is related to the dimension of Agreeableness. Namely, in this domain, the facets of Trust and Compliance had the highest scores in alcohol-dependent women, compared with opiate-dependent and control groups, which is not supported by the results of some other studies (Sher et al. 2000, Laursen et al. 2002). Although these differences did not reach statistically significance in comparison with control group, our findings tended to raise an important question related to the fact that alcohol-dependent women presented themselves as persons who have the most trust and the highest willingness to cooperate.

Similar results have been obtained by Anderson et al. (1999). These authors emphasized that main predisposition for alcohol abuse in females could be attributed to social rather than personal factors, which is not observed in male population. Therefore, bearing in mind that Trust and Compliance contain a number of social environment components, we could expect a higher degree of variability in these scores relative to the remaining facets and dimensions of the NEO-PI-R. 
Some limitations of the present study need to be kept in mind in interpretation of the results. Firstly, the addicted sample was composed of consecutive series of females attending outpatient departments of the Special Hospital for Addiction Diseases in Belgrade, who could have different characteristics from those not seeking medical care during the observed period. Therefore, it should be recognized that findings obtained in such specific clinical settings cannot be easily generalized to wider substance-dependent female population. In addition, the study could benefitted from a larger sample size, especially in terms of discussing the findings at facets level of the NEO-PI-R. Secondly, cross-sectional study design captures association but does not allow for causality or temporal sequence to be assessed. Thirdly, an information bias should be acknowledged, because data obtained through the NEO-PI-R questionnaire are selfreported.

\section{CONCLUSION}

The results of our study confirmed significant diferences in personality profiles among females who had alcohol and opiate dependence, as well as the difference between these two groups of substance abusers and their healthy age-matched controls. Moreover, our findings indicated that Neuroticism predisposes women to both alcohol and opiate use disorders (i.e., acts as a general predisposing factor). High levels of Extraversion (particularly excitement seeking), low levels of Agreeableness (particularly low trust) and low levels of Conscientiousness (particularly low self-discipline, low sense of duty and low deliberation) predisposed women to opiate addiction. Women addicted to opiates tend to be generally younger, whereas those addicted to alcohol were generally older than controls. In addition, women addicted to opiates showed much less socio-economic stability, tended to be less educated, single, unemployed and not having children. Also, women expressing higher levels of Neuroticism, but 'healthy' in other NEO-PI-R dimensions, coupled with stable social roles and stable family rather chose alcohol over opiates. Thus, these results could have important ramifications for prevention, treatment planning and future research in this specific cohort. Moreover, it has been well recognized that females with the most common symptoms of depression could be considered as particularly vulnerable group for development of alcohol and/or opiate dependence. Keeping in mind this fact, screening of personality profile characteristic related to increased risk for this kind of addiction, among this susceptible cohort, could be the core of more effective approaches in the prevention of substance abuse.

However, it should be mentioned that the inefficient policy against trafficking in drugs in the transitional society of the Republic of Serbia made access to both of these substances available, in spite the fact that heroin is formally illegal, as opposed to alcohol. In other words, it is more likely that personality features determine the choice, rather than the substance-related availability.

\section{Acknowledgements:}

None of the authors received grants for the present study. Darija Kisic Tepavcevic and Tatjana Gazibara were supported by grant from the Ministry of Education and Science of the Republic of Serbia (project no. 175087) for other projects.

\section{Conflict of interest: None to declare.}

\section{Contribution of individual authors:}

Diana Raketic made substantial contributions to conception and design, literature searches and analyses, acquisition of data, and analysis and interpretation of data and also participated in drafting the article or revising and giving the final approval of the version to be submitted.

Jasmina V. Barisic made substantial contributions to analysis and interpretation of data also participated in revising the article and giving the final approval of the version to be submitted.

Snezana M. Svetozarevic made substantial contributions to literature searches and analyses, analysis and interpretation of data from the perspective of the psychology, and also participated in drafting the manuscript and revising.

Tatjana Gazibara has been involved in critically revising of the manuscript for important intellectual content.

Darija Kisic Tepavcevic made substantial contributions to conception of the study, and has been involved in drafting the manuscript.

Srdjan D. Milovanovic made substantial contributions to conception and design, participated in revising the article and gave final approval of the version to be submitted.

\section{References}

1. Abulseoud OA, Karpyak VM, Schneekloth T, Hall-Flavin DK, Loukianova LL, Geske JR et al.: A retrospective study of gender differences in depressive symptoms and risk of relapse in patients with alcohol dependence. Am J Addict 2013; 22:437-442.

2. Acton GS: Measurement of impulsivity in a hierarchical model of personality traits: implications for substance use. Subst Use Misuse 2003; 38:67-83.

3. Akiskal HS, Hirschfeld RMA, Yerevanian BI: The relationship of personality to affective disorders. Arch Gen Psychiatry 1983;40:800-810.

4. Anderson RE, Barnes GE, Patton D, Perkins TM: Personality in the development of substance abuse. Pers Psychol Eur 1999; 17:141.

5. Barnes GE: Clinical and prealcoholic personality characteristics; a reanalysis of the litrature. In Kissin $B$ \& Begleiter $H$ (eds.): The biology of alcoholism: Vol. 6. The pathogenesis of alcoholism: psychosocial factors, 113-195. New York: Plenum Press, 1983.

6. Brady JE, Li G: Trends in alcohol and other drugs detected in fatally injured drivers in the United States, 1999-2010. Am J Epidemiol 2014; 179:692-699.

7. Boykoff N, Schneekloth TD, Hall-Flavin D, Loukianova L, Karpyak VM, Stevens SR et al.: Gender differences in the relationship between depressive symptoms and cravings in alcoholism. Am J Addict 2010; 19:352-356. 
8. Brooner RK, Herbst JH, Schmidt CW, Bigelow GE, Costa PT: Antisocial personality disorder among drug abusers. Relations to other personality diagnosis and the FiveFactor Model of Personality. J Nerv Ment Dis 1993; 181:313-319.

9. Brooner RK, Schmidt CW, Herbst JH: Personality trait characteristics od opioid abusers with and without peronality disorders. In Costa PT \& Widiger TA (eds): Personality disorders and five-factor model of personality, 131-148, Washington; American Psychological Association; 2002.

10. Brown CG, Stewart SH: Exploring perceptions of alcohol use as self-medication for depression among women receiving community-based treatment for alcohol problems. J Prev Interv Community 2008; 35:33-47.

11. De Wit H: Impulsivity as a determinant and consequence of drug use: a review of underlying processes. Addict Biol 2009; 14:22-31.

12. Dubey C, Arora M, Gupta S, Kumar B: Five Factor Correlates: A Comparison of Substance Abusers and Non-Substance Abusers. J Indian Acad Appl Psychol 2010; 36:107-114.

13. Flory K, Lynam D, Milich R, Leukefeld C, Clayton R: The relationship among personality, symptoms of alcohol and marijuana abuse, and symptoms of comorbid psychopathology: Results from a community sample. Exp Clin Psychopharmacol 2002; 10:425-434.

14. Harrell ZA, Slane JD, Klump KL: Predictors of alcohol problems in college women: the role of depressive symptoms, disordered eating, and family history of alcoholism. Addict Behav 2009; 34:252-257.

15. Hasin DS, Shmulewitz D, Stohl M, Greenstein E, Aivadyan $C$, Morita K et al.: Procedural validity of the AUDADIS-5 depression, anxiety and post-traumatic stress disorder modules: substance abusers and others in the general population. Drug Alcohol Depend 2015; 152:246-256.

16. Hopwood CJ, Morey LC, Skodol AE, Stout RL, Yen S, Ansell EB et al.: Five-factor model personality traits associated with alcohol-related diagnoses in a clinical sample. J Stud Alcohol Drugs 2007; 6:455-460.

17. Knežević G, Džamonja-Ignjatović T, Đurić-Jočić Đ: The five factor model of personality (Petofaktorski model ličnosti). Belgrade: Center for Applied Psycholog; 2004. (Serbian)

18. Kornor H, Nordvik H: Five-factor model personality traits in opioid dependence. BMC Psych 2007; 7:37.

19. Kreek JM, Nielsen AD, Butelman RE, La Forge KS: Genetic influences on impulsivity, risk taking, stress responsivity and vulnerability to drug abuse and addiction. Nat Neurosci 2005; 8:1450-1457.

20. Laursen B, Pulkkinen L, Adams R: The antecedents and correlates of agreeableness in adulthood. Dev Psychol 2002; 38:591-603.
21. Malouff JM, Thorsteinsson EB, Rooke SE, Schutte NS: Alcohol involvement and the five-factor model of personality: a meta analysis. J Drug Educ 2007; 37:277-294.

22. Milivojevic D, Milovanovic SD, Jovanovic M, Svrakic DM, Svrakic NM, Svrakic SM et al.: Temperament and character modify risk of drug addiction and influence choice of drugs. Am J Addict 2012; 21:462-467.

23. Mirnics Z, Heincz O, Bagdy G, Surányi Z, Gonda X, Benko A et al.: The relationship between the big five personality dimensions and acute psychopathology: mediating and moderating effects of coping strategies. Psychiatr Danub 2013; 25:379-88.

24. Perry JL, Carroll ME: The role of impulsive behavior in drug abuse. Psychopharmacol (Berl) 2008; 200:1-26.

25. Raketic D, Gajic-Stamatovic B, Gajic T, Jovanovic M: Women and Addiction (alcohol and opiates): Comparative analysis of psychosocial aspects. Srp Arh Celok Lek 2013; 141:648-52.

26. Robinet PM, Rowlett JK, Bardo MT: Individual differences in novelty-induced activity and the rewarding effects of novelty and amphetamine in rats. Behav Process 1998; 44:1-9.

27. Robinson EA, Brower KJ, Gomberg ES: Explaining unexpected gender differences in hostility among persons seeking treatment for substance use disorders. J Stud Alcohol 2001; 62:667-674.

28. Schmitt DP, Realo A, Voracek M, Allik J: Why can't a man be more like a woman? Sex differences in big five personality traits across 55 cultures. J Pers Soc Psychol 2008; 94:168-182.

29. Sher KJ, Bartholow B, Wood M: Personality and substance use disorders: a prospective study. J Consult Clin Psychol 2000; 68:818-829.

30. Sher KJ, Trull TJ: Personality and disinhibitory psychopathology: Alcoholism and antisocial personality disorder. J Abn Psychol 1994; 103:92-102.

31. Svrakic DM \& Cloninger RC: Epigenetic perspective on behavior development, personality disorders. Psychiatr Danub 2010; 22:153-66.

32. Tuchman E: Women and addiction: the importance of gender issues in substance abuse research. J Addict Dis 2010; 29:127-138.

33. Verdejo-García A, Lawrence AJ, Clark L: Impulsivity as a vulnerability marker for substance-use disorders: review of findings from high-risk research, problem gamblers and genetic association studies. Neurosci Biobehav Rev 2008; 32:777-810

34. Zweben JE: Special Issues in Treatment: Women. In Reis RK, Fiellin DA, Miller SC \& Saitz R (eds): Principles of addiction Medicine, 465-77. $4^{\text {th }}$ ed. Philadelphia: Lippincott, Williams \& Wilkins, a Wolters Kluwer business; 2009.

35. Walton KE, Roberts BW: On the relationship between substance use and personality traits: abstainers are not maladjusted. J Res Pers 2004; 38:515-535.

Correspondence:

Professor Srdian D. Milovanovic, $M D, P h D$

Clinic for Psychiatry, Clinical Center of Serbia

Pasterova 2, 11000 Belgrade, Serbia

E-mail:dr.srle011@gmail.com 